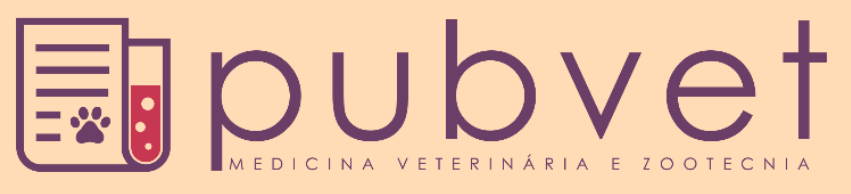

https://doi.org/10.31533/pubvet.v16n02a1044.1-10

\title{
Terapias integrativas no tratamento de equino com ferida lacerante: Relato de caso
}

\author{
Loisa Padilha Hintz ${ }^{1 \oplus}$, Natalia Miri Cunha ${ }^{2 \oplus}$, Thiago Francisco Costa Solak ${ }^{3 \oplus}$, Mariana \\ Marcantonio Coneglian ${ }^{4} \oplus$, Heloisa Godoi Bertagnon ${ }^{4 *} \otimes(0)$
}

${ }^{1}$ Médica Veterinária Especializada em Medicina de Grandes Animais, Universidade Estadual do Centro-Oeste do Paraná (Unicentro), Guarapuava, Paraná, Brasil.

${ }^{2}$ Acadêmica do curso de Medicina Veterinária, Unicentro, Guarapuava, Paraná, Brasil.

${ }^{3}$ Médico Veterinário Especializado em Medicina de Animais Selvagens, Unicentro, Guarapuava, Paraná, Brasil.

${ }^{4}$ Professora da Unicentro, Departamento de Medicina Veterinária, Guarapuava, Paraná, Brasil.

*Autor para correspondência, E-mail: hbertagnon@hotmail.com

\begin{abstract}
Resumo. Feridas lacerantes profundas são condições comuns em equinos devido a seu temperamento explosivos e o tratamento clássico normalmente é demorado, principalmente quando as condições sanitárias do animal estão comprometidas. Tendo em vista que terapias integrativas podem acelerar a cicatrização e ainda contribuir para o equilíbrio do paciente, este trabalho teve o objetivo de relatar o caso de duas lacerações profundas em membros causado por arame liso em uma potranca de dois anos de idade com baixo escore corporal. O tratamento instituído foi a associação de terapia clássica com anti-inflamatório, antimicrobiano e limpeza diária da ferida, com a integrativa a base de fitoterápicos, homeopáticos e óleo ozonizado, permitindo que o paciente obtivesse alta depois de 60 dias de sua entrada e melhora do estado geral. Em conclusão, este trabalho demonstra que a abordagem holística do paciente permitiu uma cicatrização mais rápida de feridas contaminadas em comparação aos achados de literatura.
\end{abstract}

Palavras-chave: Bem-estar, cicatrização, fitoterapia, homeopatia, ozonioterapia

\section{Integrative therapies in equine treatment with lacerating wound: Case Report}

\begin{abstract}
Deep lacerating wounds are common conditions in horses due to their explosive temperament and the classical treatment is usually time consuming, especially when the sanitary conditions of the animal are compromised. Considering that integrative therapies can accelerate healing and contribute to the balance of the patient, this study aimed to report the case of two deep lacerations in limbs caused by smooth wire in a two-year-old filly with a low body score. The treatment instituted was the association of classical therapy with anti-inflammatory, antimicrobial and daily cleaning of the wound, with the integrative based on herbal medicine, homeopathic and ozonated oil, allowing the patient to be discharged after 60 days of her admission and improvement of her general condition. In conclusion, this paper demonstrates that the holistic approach to the patient allowed for faster healing of contaminated wounds compared to the literature findings.
\end{abstract}

Keywords: Animal welfare, cicatrization, homeopathy, ozone therapy, phytotherapy

\section{Introdução}

Em decorrência do seu comportamento reativo, os equinos estão predispostos a acidentes com objetos estranhos que resultam em feridas graves como lacerações, abrasões e contusões, o que 
representa 63\% de incidência na clínica equina (Paganela et al., 2009; Pessoa et al., 2014). Mesmo que comprometam apenas as camadas da pele, tais ferimentos podem levar a complicações como enfisema subcutâneo devido contaminação por bactérias produtoras de gás e quebra de homeostase da pele, o que retarda a cicatrização e prolonga a dor e a inflamação local. Tal condição promove o emagrecimento do animal, afeta seu bem-estar e pode ainda ser agravado por casos de laminite endotoxêmica ou mecânica e tétano (Bonacin et al., 2018; Di Filippo et al., 2016; Laskoski et al., 2015; Thomassian, 2005).

O processo de cicatrização das feridas é dividido em três etapas: inflamatória, de proliferação e de remodelamento. A primeira dura cerca de 96 horas e é onde ocorre a ativação da cascata de coagulação e estancamento da hemorragia, a segunda se dá pela formação do tecido de granulação e se prolonga até os 20 a 30 dias pós-lesão e por fim, a última promove a deposição organizada de colágeno e fechamento do tecido que pode perdurar por até 12 meses (Oliveira \& Dias, 2012). Entretanto, qualquer uma dessas fases pode ser afetada pela presença de contaminação, corpos estranhos na ferida ou hipóxia tecidual, bem como má nutrição e doenças intercorrentes (Moraes et al., 2014).

O clínico deve apoiar a sua abordagem terapêutica nas fases cicatriciais supracitadas, avaliando diariamente a necessidade e evolução da ferida (Fossum, 2014). Para isso, é possível a utilização de medicamentos alopáticos e de terapias complementares, como acupuntura, ozonioterapia, homeopatia, fitoterapia, fisioterapia, aromaterapia, laser terapia, reiki e de eletroterapia, de forma isolada ou em associações, que juntamente coma terapia clássica tem diminuído o tempo de cicatrização das feridas (Kondo \& Kawamoto, 2014; Lopes, 2010; Viana et al., 2014; Villas-Boas et al., 2017), com possibilidades de influenciar no animal como um todo, restabelecendo seu equilíbrio e garantido seu bem estar.

Considerando a incidência de equinos com lesões por objetos estranhos e as terapias comumente utilizadas, o objetivo deste trabalho foi relatar o caso de uma potranca debilitada em decorrência de acidente com arame liso e discutir o impacto das terapias integrativas na sua recuperação rápida.

\section{Relato de caso}

No dia 29 de setembro de 2020, atendeu-se no Setor de Grandes Animais da Clínica Escola Veterinária Prof. Dr. Marcos Vinicius Tranquilim (CEVET) da Universidade Estadual do Centro Oeste do Paraná (UNICENTRO), uma potranca de dois anos, $225 \mathrm{~kg}$ de peso vivo e de pelagem pampa, com queixa de ferida aberta em axila direita. Durante a anamnese, relatou-se que o animal era mantido em piquete com mais dois contactantes da mesma espécie e, 5 dias antes, foi encontrado com o membro torácico direito (MTD) enroscado em uma cerca de arame liso. Após o animal ter sido socorrido pelo tratador, recebeu terapia com fenilbutazona via oral e antibiótico a base de Benzilpenicilina procaína intramuscular uma vez ao dia durante três dias, entretanto quatro dias depois, o proprietário observou uma ferida profunda na região do incidente e solicitou o atendimento da equipe veterinária, levando o animal para internamento e tratamento na CEVET.

Quanto ao histórico do animal, informou-se que ao nascimento, a potranca foi diagnosticada com flacidez de tendão e que no início do ano de 2020 ficou enroscada em uma corda, lesionando a pele em região de boleto do membro torácico esquerdo, nos dois casos o animal foi avaliado por um veterinário, tratado e se recuperou. Ademais, foi informado que todos os animais da propriedade receberam vacina contra tétano, raiva, encefalomielite e influenza em dezembro de 2019, mas que o combate contra parasitas internos e externos não era regular.

Ao exame físico, o animal apresentava um escore de condição corporal (ECC) de 2 (na escala de 1 a 5), pelame seco e arrepiado, taquicardia (50 batimentos por minuto), taquipneia ( 28 movimentos por minuto), temperatura retal de $37,7^{\circ} \mathrm{C}$, mucosas normocoradas, movimentação intestinal de acordo com o esperado para a espécie e sem linfonodos reativos, entretanto o tempo de preenchimento capilar era de quatro segundos, permitindo a determinação de um grau de desidratação de 6 a $8 \%$.

Durante o exame específico do sistema tegumentar, constatou-se a presença das seguintes alterações: ferida lacerada de $15 \mathrm{~cm}$ de profundidade e $30 \mathrm{~cm}$ de extensão no sentido cranio-caudal (CC) em região axilar de MTD; abrasão de $30 \mathrm{~cm}$ de comprimento no sentido CC por $5 \mathrm{~cm}$ de largura em porção medial da coxa direita com aspecto necrótico; escoriação de $5 \mathrm{~cm}$ de diâmetro ventral a vulva; escara de decúbito em extremidade óssea de articulação coxofemoral esquerda; enfisema subcutâneo nas regiões 
escapular do MTD, cervical direita e peitoral; infestação por carrapatos da espécie Rhipicephalus microplus identificados pelo Laboratório de Doenças Infecciosas e Parasitárias da UNICENTRO e por fim, alopecia generalizada em face e pescoço.

Devido a claudicação de grau 4 em MTD e de grau 1 em membro pélvico direito (MPD), realizouse exame específico do sistema locomotor, onde foi possível constatar que não houve comprometimento de tendões, ligamentos ou ossos. Portanto, os ferimentos do animal abrangiam apenas pele e musculatura, permitindo que o quadro apresentasse um prognóstico favorável. Considerando o histórico e o quadro do animal e buscando a certeza do melhor tratamento, solicitou-se exame hematológico em que se pode constatar a ocorrência de anemia (hematócrito de $22,2 \%$ ), leucocitose por neutrofilia e hiperfibrinogenemia (Tabela 1).

Visto que o animal foi levado às pressas para o atendimento, não foram realizados os exames obrigatórios para o transporte de equinos: Anemia Infecciosa Equina e Mormo. Levando isso em conta, também foi realizada colheita sanguínea para diagnóstico de tais enfermidades, obtendo-se resultado negativo para ambas.

Portanto, deu-se início ao tratamento do animal, que foi submetido a exame físico minucioso duas vezes por dia e protocolo terapêutico para controle da dor com uma aplicação de fenilbutazona (Fenilbutazona $\mathrm{OF}^{\circledR}$, Ouro Fino, São Paulo, Brasil) por via intravenosa (IV) na dose de $4,4 \mathrm{mg} / \mathrm{kg}$ e posteriormente, firocoxibe (Previcox ${ }^{\circledR}$, Boehringer Ingelheim, São Paulo, Brasil) por via oral (VO) na dose de $0,1 \mathrm{mg} / \mathrm{kg}$, durante sete dias, além de antibioticoterapia a partir de uma associação de sulfato de gentamicina e benzilpenicilina potássica $\left(G e n t o p e n{ }^{\circledR}\right.$, J.A. Saúde Animal, São Paulo, Brasil) na dose de 20.000UI/kg IV, BID por sete dias. Ainda fez parte do tratamento medicamentoso, administração de omeprazol (medicamento manipulado, farmácia Santa Maria, Guarapauva, PR, 2mg/kg) por sete dias com jejum prévio. Realizou-se ainda aplicação de $5 \mathrm{~mL}$ de butafosfan associado a vitamina B12 (Catofós B12 ${ }^{\circledR}$, J.A. Saúde Animal, São Paulo, Brasil) por via IV durante sete dias e por fim, mesmo que o animal possuísse histórico de vacinação, optou-se por fazer uma aplicação de soro antitetânico intramuscular (na dose de 15.000 UI) devido a gravidade da lesão por arame liso.

O enfisema subcutâneo apresentado pelo animal foi abordado a partir de massagem tópica com gel anti-inflamatório de dimetilsulfóxido (DM Gel ${ }^{\circledR}$, Vetnil, São Paulo, Brasil) e ducha fria durante 15 minutos, ambos duas vezes ao dia. A alteração teve resolução completa nos primeiros sete dias de internamento do animal, assim como a claudicação de MTD e MPD.

A abordagem inicial da ferida em axila de MTD consistiu em ducha, desbridamento de tecido necrótico, deposição de açúcar refinado para acelerar o processo de granulação e de pomadas tópicas a base de sulfadiazina de prata e de clorexidina, sendo esse protocolo realizado três vezes por dia. Como o animal estava agitado demais para o manuseio de MPD, optou-se por sedá-lo no dia seguinte com xilazina (Equisedan ${ }^{\circledR}$, J.A. Saúde Animal, São Paulo, Brasil) $(0,5 \mathrm{mg} / \mathrm{kg}$, IV) para melhor exploração da ferida, que foi lancetada e passou a drenar exsudato mucopurulento. A partir disso, realizou-se lavagem com solução fisiológica por sonda, introduzida profundamente na lesão uma vez por dia durante os primeiros sete dias.

Um dia depois, o animal recebeu um banho para retirar a sujidade e permitir a observação da condição da pele, onde foi possível notar que na escara em articulação coxofemoral, o pelo se soltava em tufos e havia presença de secreção esbranquiçada. A partir disso, a lesão passou a ser limpa diariamente com solução $\mathrm{NaCl}$ 0,9\% e receber deposição tópica de pomada a base de alantoína e óxido de zinco.

Visando uma recuperação completa do animal, realizou-se administração de suplementos a base de vitaminas, oligoelementos e aminoácidos essenciais (Hemolitan ${ }^{\circledR}$ e Glicopan Energy ${ }^{\circledR}$, Vetnil, São Paulo, Brasil), além de uma dose de vermífugo a base de Ivermectina e Pamoato de Pirantel (Equijet ${ }^{\circledR}$, J.A. Saúde Animal, São Paulo, Brasil) e duas aplicações de pour-on carrapaticida a base de cipermetrina (Ciclorfós Plus ${ }^{\circledR}$, Eurofarma, São Paulo, Brasil) com intervalo de sete dias. Ademais, o paciente foi mantido em baia com fornecimento de pasto verde recém-cortado, ração e feno de tifton, sendo retirado para a realização de exames, curativos e passeios guiados com cabresto diariamente. 
Quatro dias depois, o hemograma foi repetido (Tabela 1) e apontou para a melhora do quadro infeccioso, entretanto ainda existia anemia (hematócrito de 25,6\%). Também neste dia, a limpeza do MTD passou a ser feita duas vezes ao dia e a deposição de açúcar foi destituída.

Considerando o aspecto limpo da ferida e visando a necessidade de acelerar a cicatrização, no dia seis, a limpeza da ferida passou a ser realizada com solução fisiológica acrescida de agentes fitoterápicos (tintura de calêndula, de confrei e de mastruz) e homeopáticos (calêndula e arnica em $\mathrm{CH}$ 6), além de uso tópico de óleo ozonizado e pomada tópica a base de clorexidina. A partir disso, a profundidade da ferida reduziu gradativamente e apenas 24 dias após o internamento do animal, a ferida em MTD se tornou uma lesão superficial, na fase de remodelamento e com a extensão três vezes menor do que no início do tratamento, cicatrizando por completo 60 dias após o internamento.

Tabela 1. Hemogramas da potranca com ferida lacerante realizados antes e durante o tratamento

\begin{tabular}{|c|c|c|c|}
\hline Parâmetros & Dia zero do tratamento & Dia quatro do tratamento & Valores de referência $*$ \\
\hline \multicolumn{4}{|l|}{ Eritrograma } \\
\hline Hemácias (x106 uL) & 5 & 5,8 & $6,8-14,43$ \\
\hline Hemoglobina $(\mathrm{g} / \mathrm{dL})$ & 8,4 & 9,7 & $11-19$ \\
\hline Hematócrito $(\%)$ & 22,2 & 25,6 & $32-53$ \\
\hline VCM (fL) & 44,4 & 44,1 & $37-59$ \\
\hline $\mathrm{CHCM}(\%)$ & 37,8 & 37,9 & $31-39$ \\
\hline \multicolumn{4}{|l|}{ Leucograma } \\
\hline Leucócitos totais $\left(\mathrm{x} 10^{3} / \mathrm{uL}\right)$ & 17,63 & 8,766 & $5,4-14,3$ \\
\hline Bastonetes (x $\left.10^{3} / \mathrm{uL}\right)$ & - & 0,09 & $0-0,1$ \\
\hline Segmentados $\left(\times 10^{3} / \mathrm{uL}\right)$ & 12,87 & 2,28 & $2,26-8,58$ \\
\hline Eosinófilos $\left(\times 10^{3} / \mathrm{uL}\right)$ & - & 1,23 & $0-1$ \\
\hline Basófilos (x103/uL) & - & 0,18 & $0-0,29$ \\
\hline Linfócitos (x103/uL) & 4,94 & 4,91 & $1,5-7,7$ \\
\hline Monócitos (x103/uL) & & 0,09 & $0-0,1$ \\
\hline \multicolumn{4}{|l|}{ Demais componentes sanguíneos } \\
\hline Plaquetas $\left(\mathrm{x} 10^{3} / \mathrm{mm}^{3}\right)$ & 389 & 255 & $100-350$ \\
\hline Fibrinogênio $(\mathrm{mg} / \mathrm{dL})$ & 600 & 200 & $100-400$ \\
\hline Proteína plasmática total (g/dL) & 8 & 7 & $5,8-8,7$ \\
\hline
\end{tabular}

*Feldman et al. (2010).

Tratando-se da ferida de MPD, a mesma solução fitoterápica e homeopática foi utilizada, permitindo remover facilmente a pele necrosada o dia 14. A partir disso, o tecido subjacente passou a granular de forma rápida e a pele cicatrizou por completo no dia 60. A evolução das feridas de MTD e MPD estão expostas nas Figuras 1 e 2 respectivamente.

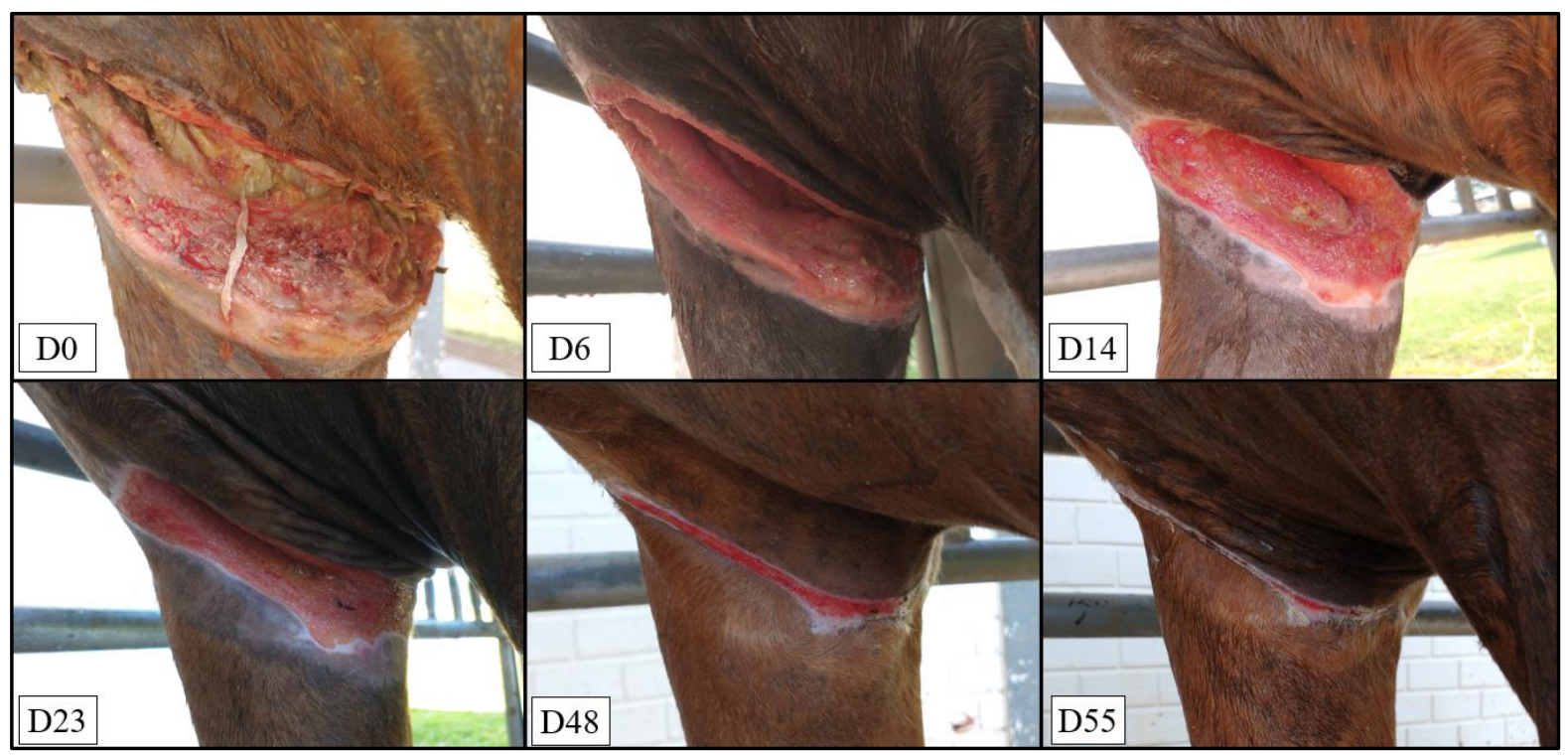

Figura 1. Evolução da ferida em membro torácico direito de equino internado e tratado no Setor de Grandes Animais da CEVET/UNICENTRO; 


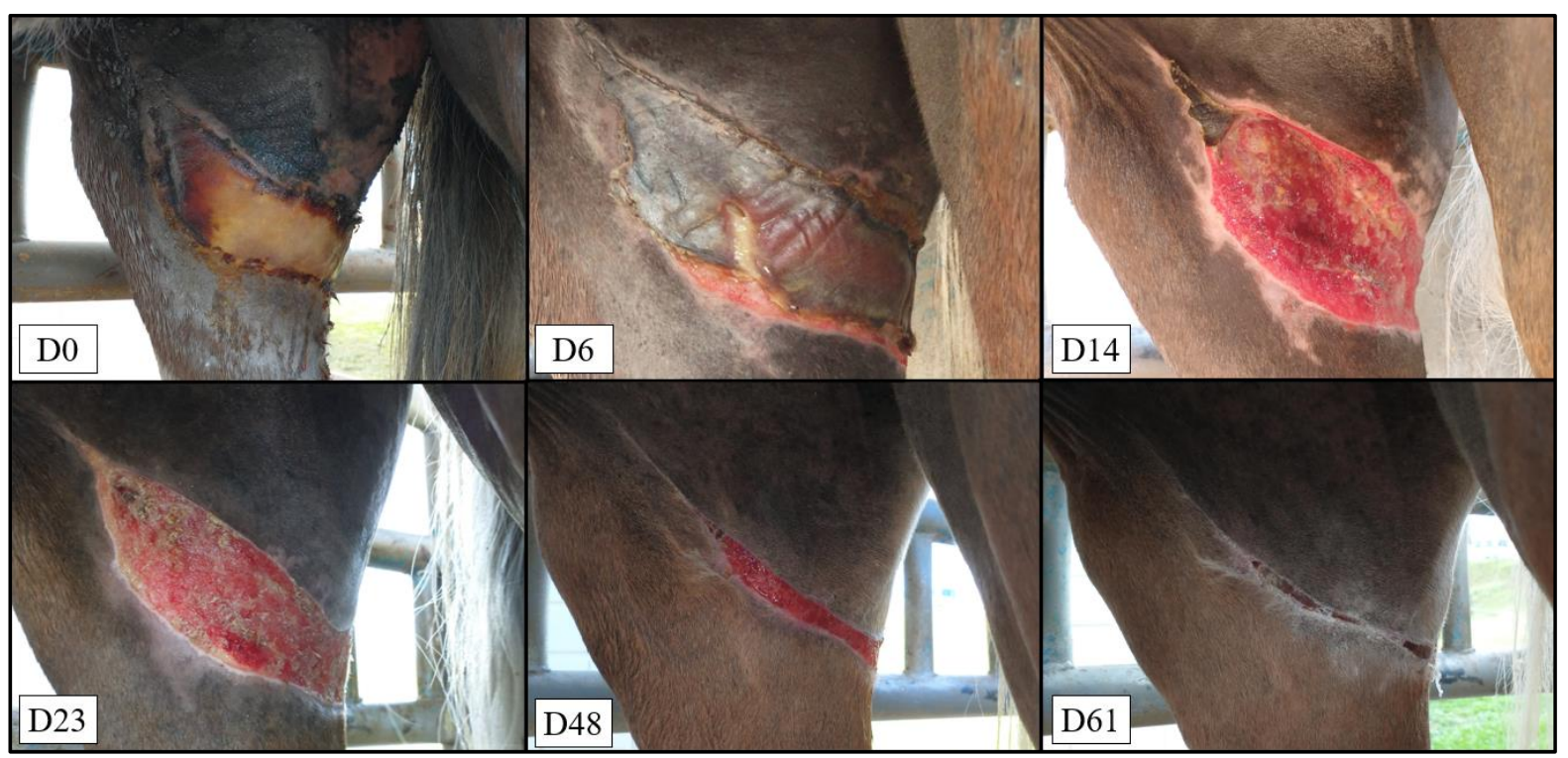

Figura 2. Evolução da ferida em membro pélvico direito de equino internado e tratado no Setor de Grandes Animais da CEVET/UNICENTRO.

Ao longo do seu internamento e de forma esporádica, o animal apresentou claudicação leve de membro pélvico esquerdo, alteração esta que não teve a sua causa completamente elucidada e aparentava ser uma alteração motora sem sensibilidade dolorosa. Portanto, aos 61 dias de internamento, o animal se mostrou livre da infestação por carrapatos, com resolução da alopecia generalizada, cicatrização completa das feridas em membro torácico direito, membro pélvico direito e um ganho de peso de $60 \mathrm{~kg}$ de peso corpóreo, resultando em um ECC de 3,5 (de 1 a 5) (Figura 3). Com isso, concedeu-se a alta hospitalar com recomendações para manutenção do estado geral e conforto do paciente.

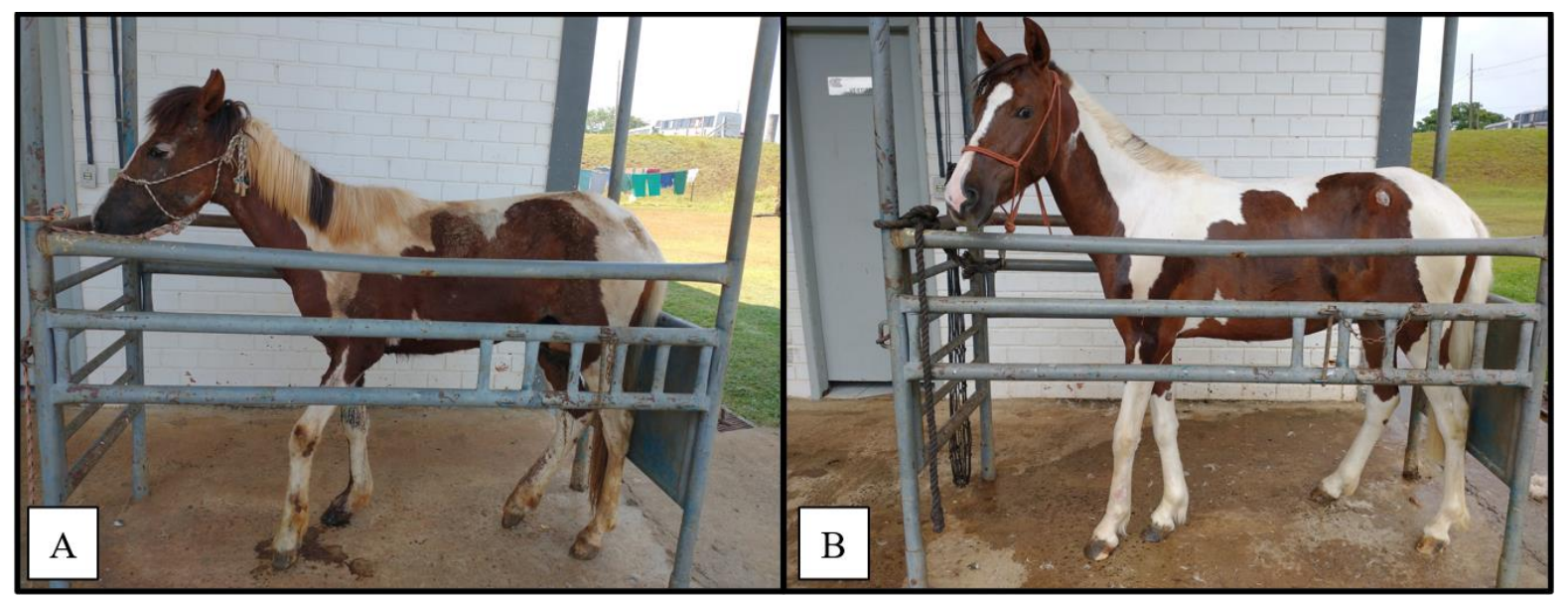

Figura 3. Início e término do tratamento de potranca internada no Setor de Grandes Animais da CEVET/UNICENTRO com laceração profunda em membros anterior e posterior direitos. Evolução do estado geral do paciente A- dia zero e Bdia 60 .

\section{Discussão}

A incidência de equinos com lesões cutâneas causadas por objetos estranhos foi observada por Pessoa et al. (2014) no seminárido brasileiro e por Paganela et al. (2009) no sul do país. Os primeiros afirmam que, ao longo de 10 anos, $27 \%$ dos acometimentos tegumentares diziam respeito a este tipo de lesões, enquanto os sulistas afirmam que tal ocorrência é maior, alcançando $63 \%$ dos cavalos atendidos nos HCV da UFPel (RS). Tais estudos reforçam a importância de uma abordagem clínica adequada, minimizando a dor e estresse do paciente, bem como providenciando recuperação mais rápida do animal.

Dentre as complicações já mencionadas, no presente relato, observou-se apenas a presença de enfisema subcutâneo decorrente da quebra da homeostase cutânea com possível contaminação 
bacteriana, uma vez que o ferimento axilar apresentou uma extensão considerável e o animal não teve restrição de movimentos antes do atendimento, permitindo a entrada e acúmulo subcutâneo de ar na região escapular e peitoral, conforme foi descrito por Bonacin et al. (2018). O atendimento precoce e o acompanhamento diário do animal, permitiram prevenir a manifestação de um quadro de laminite, pois além do controle da dor, realizou-se acompanhamento minucioso da temperatura dos cascos e da presença de pulso digital (sinais clínicos não manifestados ao longo do internamento), além de manter o paciente em baia com cama alta, visando o conforto dos membros. Ainda foram instituídas medidas preventivas contra tétano, por mais que existisse o histórico de vacinação, visando a garantia de que a enfermidade não acometesse o paciente.

Buscando o controle da dor, o emprego de fenilbutazona IV é realizado mediante sua rápida ação e afinidade com o sistema musculoesquelético (Ferreira et al., 2015). Entretanto, é um fármaco agressivo à mucosa estomacal e aos rins por impedir a produção de prostaglandina (Pedersen et al., 2018). Considerando o histórico do animal, optou-se pela utilização de omeprazol como protetor gástrico, uma vez que tal fármaco age inibindo a bomba de prótons, além da substituição da fenilbutazona por firocoxibe, uma vez que este é um fármaco inibidor da cox-2 e por isso, agride menos a mucosa do estômago do animal (Hilário et al., 2006). Entretanto, do ponto de vista analgésico, Doucet et al. (2008) afirmam que os anti-inflamatórios não-esteroidais tem potência analgésica semelhante quando utilizados para controle da dor de afecções musculares.

Carmo et al. (2020) expõem, a realização de um hemograma é uma ferramenta útil no diagnóstico e acompanhamento de um paciente, uma vez que aponta quais células sanguíneas estão em quantidade ou morfologia alteradas e auxilia na explicação de determinados sinais clínicos. A partir dos dados encontrados no hemograma inicial do presente relato, é possível afirmar que o animal apresentava: uma anemia normocítica normocrômica provavelmente pela deficiência de ferro e de B12 devido a subnutrição e ao parasitismo; uma leucocitose com desvio à esquerda, confirmando a suspeita de uma contaminação bacteriana secundária; e uma hiperfibrinogenemia associada a resposta inflamatória aguda do organismo (Weiss \& Wardrop, 2010).

As medidas comumente utilizadas para a recuperação de um quadro anêmico são a suplementação do animal a partir de vitaminas e oligoelementos e a eliminação de parasitas. A associação de pamoato de pirantel e ivermectina tem sido descrita como eficaz no controle de endoparasitas nos equinos (Dobrowolski et al., 2016; Duarte et al., 2008), da mesma forma que a cipermetrina no combate de carrapatos do gênero Rhipicephalus sp. (Vita et al., 2012), corroborando com isso, no presente relato foi possível notar a ausência de carrapatos após a segunda aplicação do pour-on.

Em relação ao quadro infeccioso, fármacos de amplo espectro por via sistêmica no tratamento antimicrobiano são utilizados com frequência e apresentam bons resultados na espécie equina (Brito et al., 2019). Além disso, Laskoski et al. (2014) e Bonacin et al. (2018) relatam que a antibioticoterapia também é eficaz na resolução do quadro de enfisema subcutâneo decorrente de feridas cutâneas, quando somada aos demais procedimentos, como ducha e massagens. Baseado em tais relatos, é possível afirmar que o tratamento instituído foi eficaz pois tal sinal clínico teve resolução na primeira semana de tratamento.

Ao que diz respeito às feridas, Paganela et al. (2009) afirmam que estas são classificadas de acordo com o grau de contaminação (limpa, contaminada e suja) e divididas em abrasões, contusões, incisões, perfurações, hematomas e lacerações, sendo este último tipo o mais comum em equinos. Fossum (2014), explica que uma ferida extensa pode ser fechada por abordagem cirúrgica ou por segunda intenção, sendo esse último preferível quando o ferimento está contaminado, possui espaço morto sobre a pele e pouca borda cirúrgica, além do tempo decorrido desde o acidente ser maior que 24 horas. Tais características foram encontradas no presente relato e justificam a escolha da abordagem por segunda intenção.

De acordo com as fases cicatriciais citada por Oliveira \& Dias (2012), pode-se verificar que a fase inflamatória segundo a literatura teria uma duração aproximada de 96 horas, o mesmo tempo do caso em questão após o internamento, e cerca de 8 dias após a ocorrência da laceração, conforme dados do hemograma e aspecto da ferida, mostrando que o grau e contaminação realmente atrasou esta fase cicatricial. Em seguida a fase de proliferação ou granulação dura em torno de 30 dias em feridas grandes. 
No caso acompanhado esta fase durou cerca de 24 dias, mostrando que os compostos utilizados continuaram a manter a ferida livre de contaminação e ainda aceleraram esta fase.

Por fim, a fase de remodelamento com deposição organizada de colágeno, contração dos fibroblastos e fechamento de tecido, pode durar de um a 12 meses dependendo da extensão da lesão, mobilidade dos tecidos, oxigênio e temperatura (Lucas et al., 2017). No caso relatado esta fase durou cerca de 30 dias. Em comparação com a pesquisa de Lucas et al. (2017), esta cicatrização foi mais lenta que a cicatrização de feridas de $10 \mathrm{~cm}^{2}$ no tronco de equinos, mas com tempo similar a cicatrização de feridas de $10 \mathrm{~cm}^{2}$ em região de metacarpo tratada apenas com limpeza local. Cabe ressaltar que a ferida do presente relato era maior, indicando que esta fase cicatricial também foi acelerada pelo tratamento preconizado.

Ao que diz respeito a espécie equina, a cicatrização tende a ser mais complexa, devido a particularidade desses animais em produzir tecido de granulação exuberante (Pessoa et al., 2014; Viana et al., 2014), apresentarem pouca disponibilidade de tecido em membros para uma abordagem cirúrgica (Moraes et al., 2014) e o seu baixo aporte sanguíneo em determinadas regiões do corpo (Marques \& Campebell, 2017). No presente relato, por mais que a localização dos ferimentos fossem nos membros, a chance da formação de tecido de granulação exuberante era baixa, pois a ferida foi mantida limpa e apresentaram-se em região proximal de MTD e MPD.

Wilmink \& van Weeren (2004) afirmam que o conhecimento das fases da cicatrização é essencial para a decisão da abordagem terapêutica e que o protocolo sempre é passível de mudanças, visto que uma ferida apresenta diferentes necessidades em cada etapa cicatricial. Desta forma, técnicas complementares apontam ótimos resultados, como a utilização de açúcar em ferimentos extensos e profundos, devido a sua capacidade de nutrir as células lesionadas, diminuir o odor fétido e o $\mathrm{pH}$ da ferida, drenar os exsudatos e estimular os tecidos de granulação (Serafini et al., 2012).

Considerando ainda as práticas de terapia integrativa, Paganela et al. (2009) afirmam que a utilização de fitoterápicos como medidas complementares é justificável, pois certas plantas possuem a capacidade de ativar meiose e mitose de fibroblastos e acelerar o processo cicatricial. No presente estudo, a fitoterapia utilizada foi a combinação de tintura de calêndula, confrei e mastruz, e para justificar tal emprego, cita-se Martins et al. (2003) que avaliaram a eficácia de tinturas de barbatimão e calêndula no auxílio de cicatrização de feridas de equinos e puderam concluir que os compostos colaboram com o início da cicatrização das feridas nos primeiros 15 dias de experimento.

A utilização de confrei (Symphytum officinale L.) como medicamento fitoterápico é justificada pela presença de alantoína em sua composição, mostrando bons resultados em consolidação de lesões ósseas, fase final da cicatrização de feridas cutâneas, úlceras do trato gastrointestinal e tratamento de queimaduras (Ferrari et al., 2012). Da mesma forma, o mastruz (Dysphania ambrosioides) tem sido relatado como uma planta com poder cicatrizante e anti-helmíntico considerável na comunidade científica humana e veterinária (Pozzatti et al., 2010).

A homeopatia também tem ganhado espaço na medicina veterinária devido seu baixo custo e bons resultados em animais de diferentes aptidões (Braccini et al., 2019). Hostanska et al. (2012) concluíram que a utilização de arnica e calêndula em CH6 promove maior mobilidade de fibroblastos e por isso auxilia o processo cicatricial de ferimentos, sustentando a hipótese de que essa homeopatia quando utilizada no presente relato, acelerou a fase de remodelamento, além de promover melhora do comportamento do animal (Braccini et al., 2019).

Segundo Silva et al. (2018), a ozonioterapia é outra prática medicinal que vem crescendo dentro da medicina veterinária. Di Filippo et al. (2020) afirmam que a utilização de óleo de girassol ozonizado possui melhores índices de cicatrização em feridas cutâneas de equinos, quando comparados ao uso do mesmo óleo não acrescido de ozônio. Tal fato é explicado pela capacidade que o referido gás tem de reagir com os ácidos graxos do organismo, estimulando a replicação celular e acelerando o processo de cicatrização.

Ao que diz respeito do tempo de cicatrização, o presente relato teve um período menor do que o esperado e isso se deve a utilização das técnicas integrativas na abordagem terapêutica. Como método comparativo, cita-se o relato de Ribeiro et al. (2019), em que uma laceração de terceiro grau em região 
inguinal de MPD de $30 \mathrm{~cm}$ de extensão, levou 130 dias para a cicatrização completa, sendo que a abordagem terapêutica foi realizada apenas com sacarose (até o $43^{\circ}$ dia) e pomada de clorexidina.

De tal maneira, estudos avaliaram a eficácia de ketanserina (Ribeiro et al., 2009) e de um produto fitoterápico (Fitofix ${ }^{\circledR}$, Fitovet, Brasil) (Ribeiro et al., 2013) na cicatrização de feridas superficiais de apenas $5 \mathrm{~cm}$ de extensão na garupa de equinos e obtiveram como resultado o período de, 56 dias para redução das feridas e 77 dias para cicatrização completa . Ademais Barroco et al. (2016) relataram o caso de um equino com ferimento extenso em face que, a partir da abordagem cirúrgica com membrana hidrocoloide, a cicatrização completa se deu em 51 dias, período este semelhante ao presente relato, afirmando mais uma vez que a abordagem terapêutica integrativa foi eficaz para a cicatrização em segunda intenção.

A desnutrição proteica também pode atrapalhar nas três fases da cicatrização, conforme apontado por Oliveira \& Dias (2012), pois inibe a angiogênese, reduz a força tênsil dos ferimentos e diminui a produção de colágeno. Desta forma, Fürll et al. (2010) explicam que a associação entre a B12 e o butafosfan é capaz de modular respostas metabólicas, oxidando ácidos graxos, utilizando piruvato e lactato para obtenção de energia e prevenindo a oxidação de lipídeos do organismo. Portanto, a suplementação do animal realizada com butafosfan, vitamina B12, oligoelementos e nutrientes, bem como alimentação com ração comercial e pasto verde foram essenciais para garantir a manutenção e ganho de peso do animal, além da redução do estresse durante o internamento.

Ademais, o conforto ambiental e o bem-estar da paciente possibilitaram a sua recuperação de uma forma mais rápida. Isso porque, a potranca se tornou um animal de temperamento mais dócil ao longo do tratamento, permitindo um manejo adequado sem intercorrências e livre de estresses que não estivessem ligados com o seu quadro clínico (Grandin, 2014).

\section{Conclusão}

Com base nos resultados obtidos, pode-se afirmar que a terapia integrativa empregada acelerou o processo de cicatrização da ferida, uma vez que cada tratamento utilizado foi eficaz na respectiva fase cicatricial, entretanto, a soma do óleo ozonizado e das tinturas homeopáticas e fitoterápicas impulsionaram o tempo de cicatrização e promoveram ainda, um melhor comportamento, aumento do escore de condição corporal e garantia de bem-estar ao paciente.

\section{Referências bibliográficas}

Barroco, V., Prochno, H. C., Ribas, T. M. B., Botelho, G. G. K., Ziliotto, L., Escobar, A., \& Lemos, K. R. (2016). The use of a hydrocolloid dressing in the facial wound healing process of a horse-case report. Revista Acadêmica Ciência Animal, 14, 203-208.

Bonacin, Y. S., Sousa, S. S., Bueno, G. M., Chítero, A., Marques, J. A., \& Canola, P. A. (2018). Enfisema subcutâneo generalizado, decorrente de ferida perfurante em equino. Revista Acadêmica Ciência Animal, 16(1), 1-5. https://doi.org/10.7213/1981-4178.2018.162503.

Braccini, G. L., Casetta, J., Silva, S. C. C., Carniatto, C. H. O., Santos, V. D. R., \& Costa, V. F. (2019). Aplicação da homeopatia na produção animal. Revista Valore, 4, 310-323.

Brito, P. H. S., Ferreira, M. A., Prado Filho, R. R., Godoi, G. S., Mizobe, T. S. P., \& Dória, R. G. S. (2019). Bypass ileal seguido de tiflostomia no tratamento de abdomen agudo em equino. Acta Scientiae Veterinariae, 47(1), 1-6.

Carmo, B. M. B., Soares, J. M., Assis Júnior, W. G., Franco, A. A., Prado, L., Oliveira, P. G., Moreira, C. N., \& Ramos, D. G. S. (2020). Hemograma completo: ferramenta de diagnóstico na medicina veterinária. Brazilian Journal of Development, 6(7), 49989-49994. https://doi.org/10.34117/bjdv6n7-594.

Di Filippo, P. A., Graça, F. A. S., Costa, A. P. D., Santos Coutinho, Í., \& Viana, I. S. (2016). Achados clínico-epidemiológicos e resposta ao tratamento de 25 casos de tétano em equinos ocorridos na região Norte Fluminense, Rio de Janeiro, Brasil. Brazilian Journal of Veterinary Medicine, 38(1), 33-38.

Di Filippo, P. A., Ribeiro, L. M. F., Gobbi, F. P., Lemos, G. B., Ribeiro, R. B., Jerdy, H., Silva, L. C., 
Viana, I. S., \& Quirino, C. R. (2020). Effects of pure and ozonated sunflower seed oil (Helianthus annuus) on hypergranulation tissue formation, infection and healing of equine lower limb wounds. Brazilian Journal of Veterinary Medicine, 42(1), e113520-e113520.

Dobrowolski, E. C., Slompo, D., Carrasco, A. de O. T., \& Seki, M. C. (2016). Eficácia do praziquantel e da ivermectina em equinos infectados naturalmente com ciatostomíneos. Revista Acadêmica: Ciência Animal, 14, 75-81.

Doucet, M. Y., Bertone, A. L., Hendrickson, D., Hughes, F., MacAllister, C., McClure, S., Reinemeyer, C., Rossier, Y., Sifferman, R., \& Vrins, A. A. (2008). Comparison of efficacy and safety of paste formulations of firocoxib and phenylbutazone in horses with naturally occurring osteoarthritis. Journal of the American Veterinary Medical Association, 232(1), 91-97.

Duarte, E. R., Oliveira, N. J. F., Silveira, J. T., Ribeiro, F. L. A., \& Souza, R. M. (2008). Controle de verminose em equinos no norte de Minas Gerais com associação de pamoato de pirantel e ivermectina. Revista Caatinga, 21(1), 1-4.

Feldman, B.F., Zinkl, J.G. \& Jain, N.C. (2010) Schalm's veterinary hematology. 6.ed. Baltimore: Lippincott Williams and Wilkins.

Ferrari, R., Barbosa, A. M., Souza Ornelas, S., Del Lano, M. E. \& Lopes Barbosa, A. C. (2012). Confrei (Symphitum Officinale). Aspectos botânicos, fitoquímicos e terapêuticos. Ensaios e Ciência: Ciências Biológicas, Agrárias e da Saúde 16, 227-237.

Ferreira, J. C., Souza, M. V., Vilória, M. I. V., Fonseca, E. F., Vianna, M. W. S., \& Costa, J. C. M. (2015). Efeitos da Monofenilbutazona em eqüinos cicatrização por segunda intenção. Revista Ceres, $54,262-269$.

Fossum, T. W. (2014). Cirurgia de pequenos animais (4th ed., Vol. 1). Elsevier Brasil.

Fürll, M., Deniz, A., Westphal, B., Illing, C., \& Constable, P. D. (2010). Effect of multiple intravenous injections of butaphosphan and cyanocobalamin on the metabolism of periparturient dairy cows. Journal of Dairy Science, 93(9), 4155-4164. https://doi.org/10.3168/jds.2009-2914.

Grandin, T. (2014). Animal welfare and society concerns finding the missing link. Meat Science, 98 , 461-469.

Hilário, M. O. E., Terreri, M. T., \& Len, C. A. (2006). Antiinflamatórios não-hormonais: inibidores da ciclooxigenase 2. Jornal de Pediatria, 82(5), S206-S212.

Hostanska, K., Rostock, M., Melzer, J., Baumgartner, S., \& Saller, R. (2012). A homeopathic remedy from arnica, marigold, St. John's wort and comfrey accelerates in vitro wound scratch closure of NIH 3 T3 fibroblasts. BMC Complementary and Alternative Medicine, 12(1), 1-10.

Kondo, T., \& Kawamoto, M. (2014). Acupuncture and moxibustion for stress-related disorders. BioPsychoSocial Medicine, 8(1), 1-11.

Laskoski, L. M., Fioravanti, R. A. B., Doria, R. G. S., Carvalho, M. B., \& de Freitas, S. H. (2015). Enfisema subcutâneo generalizado em um equino após ferida axilar-Relato de caso. Brazilian Journal of Veterinary Medicine, 37(1), 93-96.

Lopes, D. F. (2010). Terapias complementares usadas na Medicina Veterinária. PUBVET, 4(Art-816), $1-15$.

Lucas, F. de A., Kandrotas, A. L., Nardin, E., Siqueira, C. E., André, G. S., Bromerschenkel, I., \& Perri, S. H. V. (2017). Copaiba oil in experimental wound healing in horses. Ciência Rural, 47, e20151292.

Marques, A. S., \& Campebell, R. C. (2017). Ozonioterapia em feridas de equinos-revisão. Revista Científica de Medicina Veterinária Do UNICEPLAC, 4(2), 31-45.

Martins, P. S., Alves, A. L. G., Hussni, C. A., Sequeira, J. L., Nicoletti, J. L. M., \& Thomassian, A. (2003). Comparação entre fitoterápicos de uso tópico na cicatrização de pele em eqüinos. Archives of Veterinary Science, 8(2), 1-7.

Moraes, J. M., Bravo, M. O., Mota, A. L. A. A., Dumont, C. B. S., Pereira, L. C., Ximenes, F. H. B., Maranhão, R. P. A., \& Godoy, R. F. (2014). Ultrassom terapêutico como tratamento na cicatrização de feridas em equinos. PUBVET, $8,1-8$.

Oliveira, I. V. P. M., \& Dias, R. V. C. (2012). Cicatrização de feridas: fases e fatores de influência. Acta Veterinaria Brasilica, 6(4), 267-271. 
Paganela, J. C., Ribas, L. M., Santos, C. A., Feijó, L. S., Nogueira, C. E. W., \& Fernandes, C. G. (2009). Abordagem clínica de feridas cutâneas em equinos Clinical approach in equine skin wounds. Cliências Veterinárias, 104, 13-18.

Pedersen, S. K., Cribb, A. E., Read, E. K., French, D., \& Banse, H. E. (2018). Phenylbutazone induces equine glandular gastric disease without decreasing prostaglandin E2 concentrations. Journal of Veterinary Pharmacology and Therapeutics, 41(2), 239-245.

Pessoa, A. F. A., Pessoa, C. R. M., Miranda Neto, E. G., Dantas, A. F. M., \& Riet-Correa, F. (2014). Doenças de pele em equídeos no semiárido brasileiro. Pesquisa Veterinária Brasileira, 34(8), 743748.

Pozzatti, P. N., Casagrande, F. P., Valentim, T. P., Gai, Z. T., \& Porfirio, L. C. (2010). Aspectos farmacológicos e terapêuticos da utilização da Erva-de-santa-maria (Chenopodium ambrosioides) em humanos e animais. PUBVET, 4, Art-944.

Ribeiro, G., Martins, C. B., Silva, M. A. G., Borges, V. P., \& Lacerda Neto, J. C. (2009). Uso tópico de ketanserina na cicatrização de feridas cutâneas induzidas em equinos. Arquivo Brasileiro de Medicina Veterinária e Zootecnia, 61, 144-148.

Ribeiro, G., Silva, M. A. G., Martins, C. B., Borges, V. P., \& Lacerda Neto, J. C. (2013). Associação fitoterápica no tratamento de feridas cutâneas induzidas em equinos. Arquivo Brasileiro de Medicina Veterinária e Zootecnia, 65(5), 1427-1433.

Ribeiro, R. M., Ribeiro, D. S. F., Vasconcelos, P. H. M., \& Predoza, H. P. (2019). Utilização de sacarose na cicatrização por segunda intenção em ferida de $3^{\circ}$ grau em equino: relato de caso. Interação interdisciplinar. Revista Interação Interdisciplinar (ISSN: 2526-9550), 3(1), 5-15.

Serafini, G. M. C., Schossler, J. E. W., Amaral, A. S., Dutra, L. H., Dibi, A. P., Drogemoller, P., \& Athayde, C. L. (2012). Açúcar granulado ou em gel no tratamento de feridas em cães. Ciência Rural, 42, 2213-2218.

Silva, T. C., Shiosi, R. K., \& Raineri Neto, R. (2018). Ozonioterapia: um tratamento clínico em ascensão na medicina veterinária-revisão de literatura. Revista Cientifica de Medicina Veterinária, XV(31).

Thomassian, A. (2005). Enfermidades dos cavalos. Livraria Varela.

Viana, L. F., Wenceslau, A. A., Costa, S. C. L., Figueiredo, M. A. F., Dias, F. S. S., \& Ferreira, M. L. (2014). Tratamentos complementares para ferida com tecido de granulação exuberante em um equino-Relato de caso. Brazilian Journal of Veterinary Medicine, 36(4), 417-420.

Villas-Boas, J. D., Almeida, N. A. S., Almeida, F. Q., \& Medeiros, M. A. (2017). Efeito da acupuntura nas respostas de estresse em equinos atletas submetidos a reprise de adestramento. Brazilian Journal of Veterinary Medicine, 39(4), 221-230.

Vita, G. F., Dumas, E., Pereira, M. A. V. C., \& Ferreira, I. (2012). Avaliação in vitro de carrapaticidas no controle de Rhipicephalus (Boophilus) microplus (Canestrini, 1887), no norte do estado do Rio de Janeiro, Brazil. Acta Scientiae Veterinariae, 40(2), 1-6.

Weiss, D. J., \& Wardrop, J. K. (2010). Schalm's Veterinary Hematology.

Wilmink, J. M., \& van Weeren, P. R. (2004). Differences in wound healing between horses and ponies: application of research results to the clinical approach of equine wounds. Clinical Techniques in Equine Practice, 3(2), 123-133.

\section{Histórico do artigo:}

Recebido: 27 de outubro de 2021 Aprovado: 26 de novembro de 2021

Disponível online: 3 de março de 2022
Licenciamento: Este artigo é publicado na modalidade Acesso Aberto sob a licença Creative Commons Atribuição 4.0 (CC-BY 4.0), a qual permite uso irrestrito, distribuição, reprodução em qualquer meio, desde que o autor e a fonte sejam devidamente creditados. 